\title{
Enhancing the student experience with the use of a dedicated subject website
}

Rachel Hilliam, School of Mathematics and Statistics, The Open University, Milton Keynes, UK. Email: Rachel.Hilliam@open.ac.uk

Gaynor Arrowsmith, School of Mathematics and Statistics, The Open University, Milton Keynes, UK. Email: Gaynor.Arrowsmith@open.ac.uk

\begin{abstract}
It is crucial not only to support students at all stages of their student journey, but also to create a space where they can benefit from peer support and interact with the wider mathematics and statistics (M\&S) community. In a society awash with social media, it is possible to create online spaces that complement and enhance existing communities available in traditional face-to-face courses, or to provide such an environment for students who learn at a distance. The School of Mathematics and Statistics at The Open University (OU) has recently consolidated existing resources into a website resulting in an active and vibrant community of learners. The site contains resources, which students access at appropriate points in their student journey through M\&S modules and qualifications. These resources are complemented by a number of dedicated and wellused online forums. In particular, a forum providing course choice information. Discussions in the forum have ultimately led to improvements in the structure of M\&S qualifications, influencing the content of new modules, more effective assessment strategies, and better ways of supporting students. It is a true community of learners, where everyone - students, academics and educational advisors - all contribute, learn from each other, and shape the student experience.
\end{abstract}

Keywords: Student experience, community of learners.

\section{Introduction}

Higher education has changed dramatically during the lifetime of the Open University (OU), resulting in the need for an increasing awareness of the entire student journey from first contact with the university through to becoming an alumnus. Morgan (2011) sets out the Student Experience Practitioner Model, which covers the six stages of the student lifecycle: first contact and admissions, pre-arrival, arrival and orientation, induction to study, re-orientation and re-induction, and outduction. She argues that there are five themes to consider for each stage of the lifecycle: curriculum and assessment, pedagogy, support, finance and employment. This requires staff from across the institution to be actively involved in initiatives and activities, to support the student experience. The OU has its own version of the Student Experience Model, known as the Student Seamless Journey, which encompasses all phases from the first point of contact with the $\mathrm{OU}$ to the point where the student achieves their qualification.

The School of Mathematics and Statistics has always provided opportunities for students to engage at all stages of the student journey. In the early years of the OU this happened at annual wellattended and lively meetings. These were held in numerous centres across the country, giving students the chance to talk to academics, support staff, and each other. Students had the opportunity to discuss their career aspirations and relevant module choices. Over time, attendance at these meetings started to dwindle. During the 1990s, as use of the internet increased, the School of Mathematics and Statistics capitalised on this shift by setting up an online module advice forum to both augment and to provide an alternative to the face-to-face events. The forum aimed to offer peer support and advice, in conjunction with expert input from members of the School and subjectspecialist educational advisors. In addition, resources that assisted students with their module 
choices were assembled and developed. For example, tables of examination results and student satisfaction ratings on individual modules, accumulated over several years, were provided so students could observe trends and inform their study planning. In order to deliver such information to students in an efficient way the School created a bespoke website (the M\&S programme site) which ran for many years.

In 2017, the University introduced Subject Sites with the aim of providing a home website for students throughout their qualification. The School of Mathematics and Statistics took the opportunity to develop its site as a one-stop-shop to support the student journey. The resources, which the School had been delivering for many years through the M\&S programme site, were updated and migrated to the M\&S subject site. These were arranged in such a way as to mirror, support and enhance the student journey. This report outlines many of the resources on the Subject Site and, in some cases, how these have evolved over time.

\section{The mathematics and statistics subject site}

Each Subject Site is split into six sections: Study Home, Connect, Discover, Skills, Plan and Succeed, which are generic to all Subject Sites (Figure 1). The content that populates each section is at the discretion of the owning curriculum team, except for Study Home, which conforms to a standard template. This includes links to appropriate media sites; in the case of M\&S the School's twitter and the Faculty's Facebook pages. The News and Upcoming events areas are also standard areas on every Subject Site, but the School of Mathematics and Statistics uses them in very specific ways. News provides students with news and notice of relevant events, both within the OU and in the wider mathematical and statistical community. Upcoming events is used to signpost students to relevant parts of the Subject Site at particular points of the student journey. Although the old programme site contained the supporting resources, it did suffer from a lack of facility to direct students to those resources at the particular time they needed them. Upcoming events provides this opportunity for time-dependent nudges. One such example is the reminder to students to consult Plan, which includes information about study pathways through qualifications and pre-requisites, when registration opens. Once registration is completed, students are prompted to prepare themselves for the individual module(s), under Discover, together with the Skills needed for successful study. In M\&S, as is the case for many other subjects, it is important that new students have induction that is specific to their subject. Such material is on the Discover tab, together with Are you ready? module quizzes, and Revise and refresh module preparation websites. The site not only provides a place for student engagement between modules, but also between qualifications and beyond, with each of the five main content sections having a corresponding postgraduate subsection. 


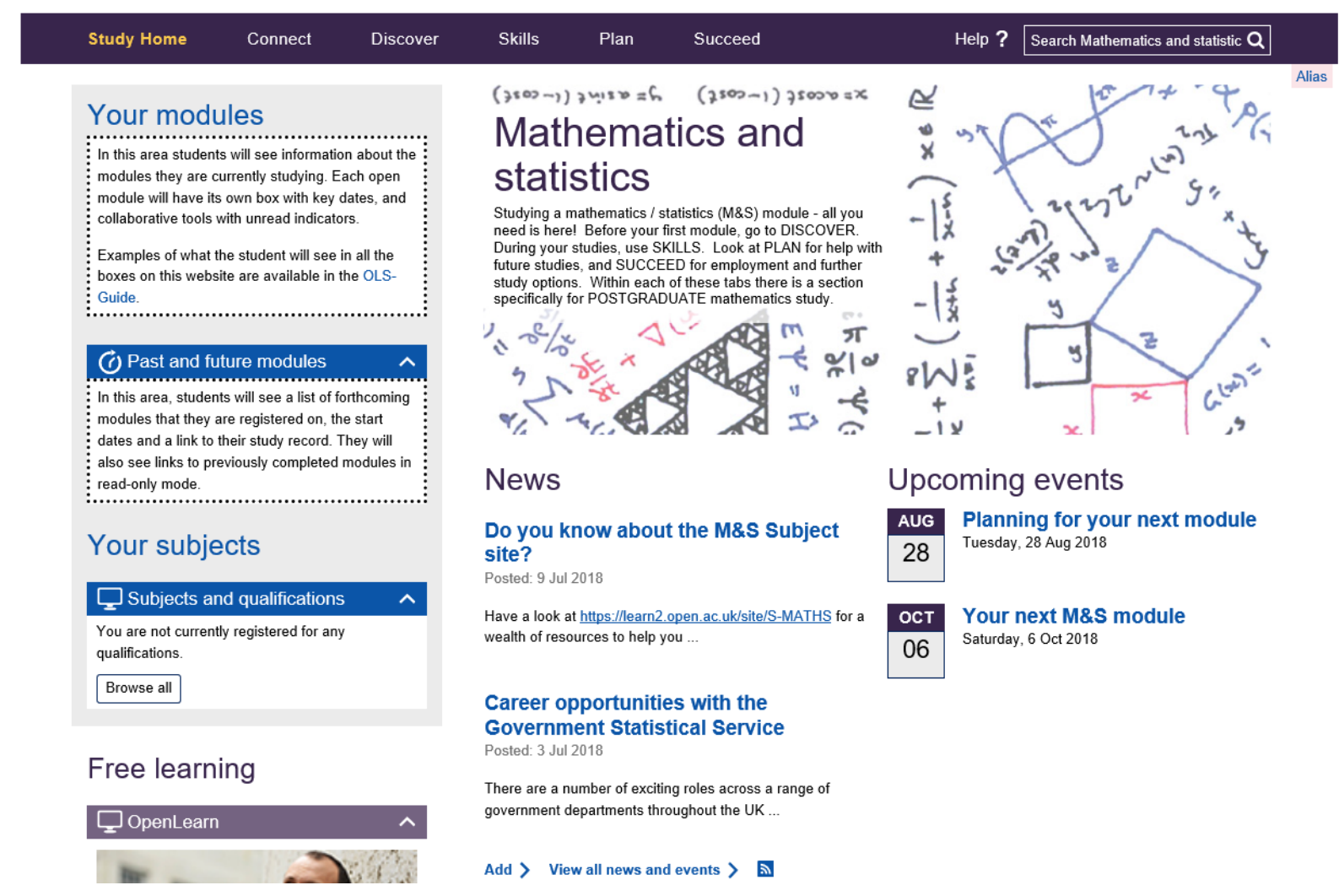

Figure 1: The Mathematics and Statistics Subject site.

\subsection{Discover}

As mathematics is a cumulative subject, the open entry policy of the Open University makes it imperative that each M\&S student starts at a point appropriate to their own mathematical expertise. There are two initial modules available to OU students. Essential Mathematics 1 (MST124) is a core option in around $20 \mathrm{OU}$ qualifications, but it does assume pre-requisite mathematical knowledge of roughly A-level standard. It is therefore possible, in a number of qualifications, for students to start with an alternative module Discovering Mathematics (MU123). Although, induction and preparatory resources for these modules are in the Discover section, new students must register onto one of these modules before they have access to the Subject Site and therefore relevant information, advice and guidance (IAG) needs to be publically available.

In 2014 a survey into the learning and teaching experiences of students, carried out by the Higher Education Policy Institute (HEPI) in conjunction with the Higher Education Academy (HEA), showed that one in five first-year students found information provided by institutions to be 'vague' (Soilemetzidis et al, 2014). It is clear that information alone is not enough to give adequate support, so it must be complemented by sufficient advice and guidance (Diamond et al, 2014). The School thus replicates and extends the IAG about these two modules on its publically available MathsChoices website, (Open University, 2018). MathsChoices sits outside the University's VLE enabling prospective students to work through the resources and ascertain their correct starting point before they begin the registration process.

In the Are you ready for? subsection of Discover there are links to self-assessed quizzes for the entire suite of undergraduate M\&S modules, plus the diagnostic quiz for entry to the MSc in Mathematics. The aim is for students to develop an awareness of the prior knowledge needed for their next module, and to identify what they need to consolidate at the start of the next stage of their journey. Student surveys and consultations have provided clear evidence that they appreciate the ability to self-diagnose their starting point: 
"I did find the diagnostic quizzes very helpful they made it very clear that MU123 was where I needed to start this course. I was free to have a go with MST124 and it was very evident from this experience that I didn't have sufficient knowledge. Also I felt my results of the diagnostic quizzes married well with the information given on the website about where the OU thought you should start. This gave me greater confidence to subscribe and get on with the course"

Students also appreciate assistance with identifying appropriate level 2 and 3 modules:

"I have used the diagnostic quizzes (AYRF...) on a few occasions, especially the level 2 and 3 maths practice prior to doing a course, and what was required for the course. It is a good way to refresh areas prior to starting a course and also testing previous knowledge - if you don't use it you lose it!"

One of the most effective ways to reduce the number of students dropping out is to identify and respond to students who are at risk (Foster et al, 2012). Evaluation has shown that each student's M124 quiz score on the Are you ready for? quiz gives the best indicator of future success on MST124 (Calvert et al, 2016). Hence there is a proactive calling campaign based on the quiz scores; one outcome of these conversations is to direct students to the Revise and Refresh for MST124 resources described below. This is another example of wrap-around support centred on the academic unit, with input from all stakeholders to develop the resource and then utilise it to full effect; thus a true community of practice (Lave and Wenger, 1991).

Students often have a study gap between one M\&S module and their next, either because they take a break in their study, and/or because they are taking M\&S modules as part of a non-M\&S qualification. In order for a student to brush up their mathematical knowledge and skills before embarking on the next stage of their journey there are Revise and refresh (R\&R) resources in the Discover area. These resources give students the chance, before starting their next module, to consolidate their learning, re-visit and practice key topics, and improve in areas where they may not have fully engaged in previous study. In each section, the resources include quizzes, short explanatory texts, screencasts of worked examples, tutor-moderated forums, and boot-camp style tutorials, which are timetabled to run in the break between modules. Each $\mathbf{R} \& \mathbf{R}$ subsection, focusses on an individual topic. Students are able to self-diagnose what they need to revise by taking the quiz for particular topic (Figure 2). The quiz can be repeated multiple times to enable students to check their progress. There are brief refresher materials and cross-references to where the topic is in the pre-requisite module, and screencasts where a tutor talks through how they tackle a typical example. For each topic there are exercises which the students can use to practice their skills, and a tutormoderated forum for them to ask further questions. 


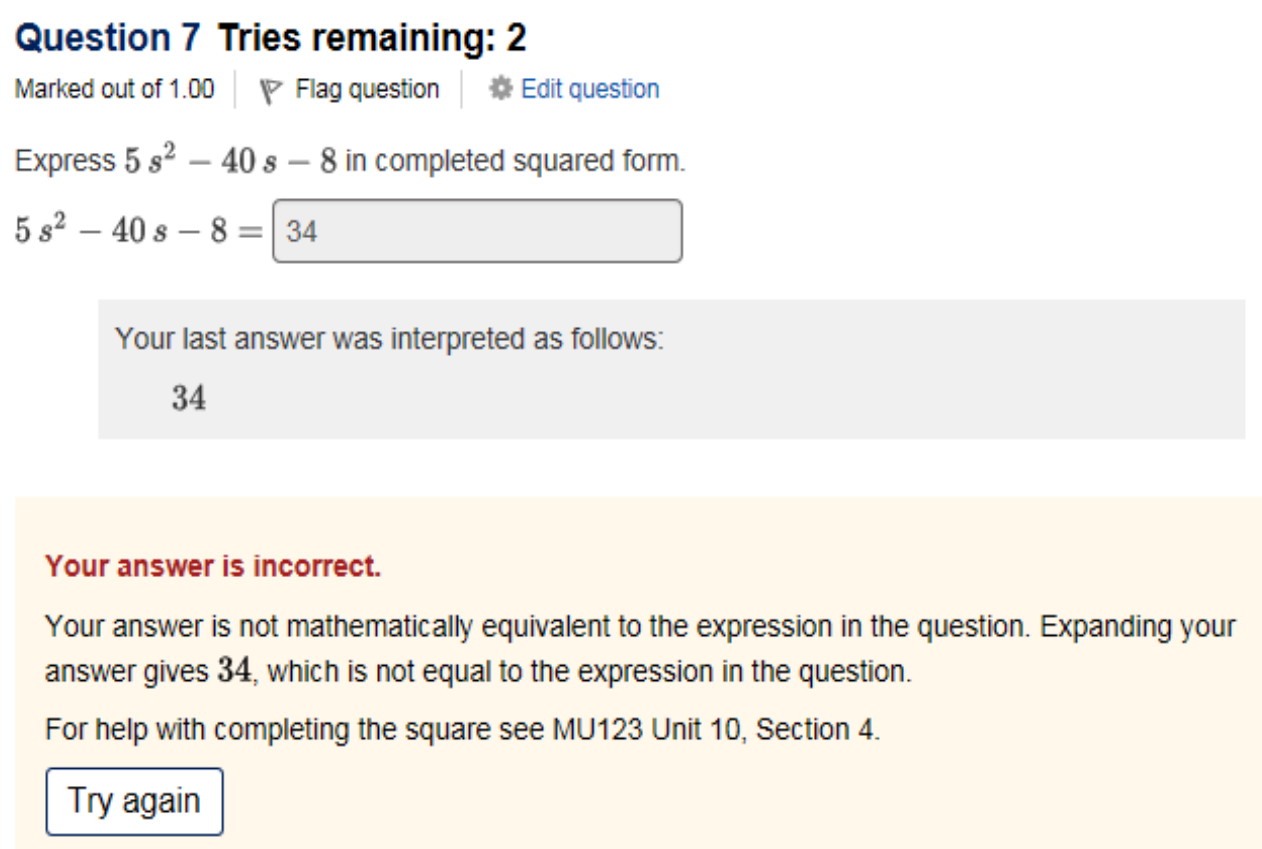

Figure 2: Revise and Refresh for MST124: Quadratic expressions and equations quiz

The provision of taster material for both undergraduate and postgraduate students is very important, and the Discover your module section of Discover has sample units from every undergraduate and postgraduate module. Students comment on the benefits of such resources:

"I am grateful that we can download the first two chapters of the next module ahead of time, so you can take a couple of hours here and there (on the train, waiting for a flight or just downtime you have at home) to look at things with no time pressure, ease yourself slowly back into it and get a feeling for the course".

The combination of Are you ready? quizzes, Revise and refresh resources and the sample content in Discover your module aims to ensure that students choose appropriate modules, and have the appropriate pre-requisite knowledge when moving onto their next module.

\subsection{Skills}

The Skills section contains advice about how to study mathematics and statistics modules effectively. There is a subpage entitled Learning mathematics and statistics which has resources covering a range of study skills specific to M\&S these include: How to study mathematics and statistics effectively, Problem solving, Writing mathematics and statistics, and Mathematical proof, with plans for sections on Mathematical modelling and Working with Data. A further recommendation from Foster et al (2012) is to ensure there is good communication about, and access to, additional student support. In order to achieve this there is a dedicated section on overcoming accessibility issues when studying mathematics and statistics, containing detailed information for students who need additional resources and alternative formats. The Skills section also contains pages on Good academic practice and Plagiarism, Assessment preparation and submission, Advice about examinations and Calculators, because each of these aspects has specific connotations in the context of studying M\&S. Finally, there are resources dedicated to helping students with Typing mathematical notation, and about the Software used in mathematics and statistics modules. 


\subsection{Plan}

When registration opens each year, students are reminded, via the Upcoming events, about the information under Plan. The Plan resources include a collated table of the last four years of pass and completion rates for each M\&S module, and a further table giving the last four years of student feedback from in-house student-satisfaction module surveys. Although this information is published elsewhere, it is not readily available and certainly not collated together in an easily comparable format. Plan also provides a location in which to outline any proposed significant changes to, or new, curriculum.

\subsection{Succeed}

The School of Mathematics and Statistics has run several subject-focussed careers events, and therefore has close links with the University's central careers service. There is evidence that only a small number of undergraduate students feel they have really developed the skills necessary to help them get a job, such as CV writing or career planning (Neves, 2016). Whilst a number of OU students are studying whilst in employment, many are looking to change career and a growing number are full time students yet to enter the job market. Therefore, the Succeed section includes; general careers advice, guidance around what employers are looking for in job applications; ways in which students can enhance their employability through developing specific expertise; advice and guidance on job-seeking and making an application. There is also advice on studying beyond an undergraduate degree. Most of these resources were produced through collaborative work between the central OU careers service and the School of Mathematics and Statistics.

\subsection{Connect}

Whilst each of the tabs on the subject site provides IAG for the student journey this does not in itself create a community. Crosling et al (2008) state that "Students are far more likely to continue with higher education if they are engaged in their studies and have developed networks and relationships with fellow students." This is exactly what the Connect tab provides. There are some dedicated timelimited forums for Revise and refresh, Early start and other specific events. As many students are working towards an M\&S teaching career whether that be Primary, Secondary or Further Education, there is a specialist forum for topical issues related to mathematics education. However, the heart of the entire subject site is the mathematics and statistics advice forum. In that forum the entire M\&S community (students, tutors, academics and support staff) discuss future study plans, how different modules may help with future careers and what it is like to study particular modules. Essentially anything related to module choice and study planning. In addition, students provide firsthand feedback on all aspects of the student experience in terms of both curriculum development and general student support. As one student expressed, it is "the most interesting forum provided by the OU". Its success lies in the wide range of contributors and the acceptance that everyone is listened to. It is held up as the blueprint all Schools should aspire to in terms of providing a space for student feedback. Internal publications and events delivered by the School have provided advice for other OU Schools when developing their resources to populate their own subject sites.

\section{Conclusion}

The School of Mathematics and Statistics has a long tradition of providing IAG, in a variety of forms, to help students make informed decisions regarding their own study. The value of creating an M\&S community has always been important, especially when face-to-face opportunities diminished, and the School embraced new online ways of achieving this. The advice forum is a jewel in the School's crown, and is not only seen by students as the go-to place for asking questions about module choice and study planning, but as a mechanism for their contributions and opinions to lead directly to improvements in qualification and module delivery. The importance of making changes, based on their feedback, means that students feel that they are a valued part of the learning community 
(Howson, 2014). The M\&S Subject Site is a place where students, tutors, academics and support staff feel empowered and equally valued in their contributions. All contributors reference relevant areas within the site in response to questions, and those resources, and the way they are organised, mirror the student journey and enhance the student experience. The M\&S Subject Site is a resource for a true community of learners in mathematics and statistics provided by an active community of practice.

\section{References}

Calvert, C., Hilliam, R., and Coleman, J., 2016. Improving retention for all students, studying mathematics as part of their chosen qualification, by using a voluntary diagnostic quiz, MSOR Connections 14(3), pp.28-31.

Crosling, G., Thomas, L. and Heany, M., 2008. Improving Student Retention in Higher Education The role of teaching and learning. London: Routledge.

Diamond, A., Roberts, J., Vorley, T., Birkin, G., Evans, J., Sheen, J., and Nathwani, T., 2014. UK review of the provision of information about higher education: Advisory Study and Literature Review. Leicester: CRE Research.

Foster, E., Lawther, S., Keenan, C., Bates, N., Colley, B., and Lefever R., 2012. The HERE Project: Higher Education: Retention \& Engagement. London: Paul Hamlyn Foundation.

Howson, C.B.K., 2014. Feedback to and from students: Building an ethos of student and staff engagement in teaching and learning. In H. Fry, S. Ketteridge and S. Marshall [eds.]. A Handbook for Teaching and Learning in Higher Education. Oxon: Routledge. pp.123-138.

Lave, J., and Wenger, E., 1991. Situated Learning: Legitimate Peripheral Participation. Cambridge: Cambridge University Press.

Morgan, M., 2011. Improving the Student Experience: A practical guide for universities and colleges. Oxon: Routledge.

Neves, J., 2016. Student Engagement and Skills Development - The UK Engagement Survey. York: The Higher Education Academy.

Open University, 2018. MathsChoices website. Available at: http://mathschoices.open.ac.uk [Accessed 11 March 2019].

Soilemetzidis, I., Bennett, P., Buckley, A., Hillman, N., and Stoakes, G., 2014. The HEPI-HEA Student Academic Experience Survey 2014. York: Higher Education Academy. 